\title{
Should ethanol be considered a treatment for COVID-19?
}

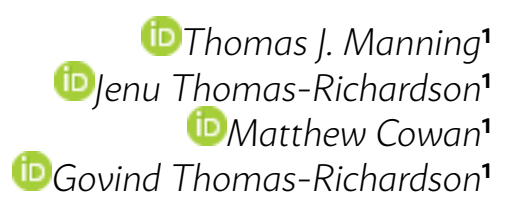

1. Valdosta State University, Valdosta, USA.

http://dx.doi.org/10.1590/1806-9282.66.9.1169
Dear Editor,

The Coronavirus has impacted the global community and currently has hot spots in their first phase'. There are no treatments or vaccines that are universally recognized by the medical communities. The use of alcohol, specifically, ethanol, is ubiquitous with disinfection practices in venues including healthcare facilities, such as hospitals and medical practices, K-12 schools and higher education institutions, workplaces ranging from office buildings to manufacturing facilities, transportation hubs, and military bases worldwide. In addition, there is a significant volume of peer-reviewed literature that focuses not only on ethanol's general disinfection properties but also its anti-viral properties ${ }^{2-5}$.

Ethanol has been shown to have a direct impact on human coronaviruses such as Severe Acute Respiratory Syndrome (SARS) coronavirus, Middle East Respiratory Syndrome (MERS), coronavirus (endemic) human coronaviruses (HCoV). These viruses can exist for several days on surfaces like plastic and glass. It has been demonstrated that disinfectant agents can effectively reduce coronavirus infectivity in a very short time ( $<60$ seconds). For example, ethanol is $62 \%-71 \%$, effective, hydrogen peroxide is $0.5 \%$ effective, sodium hypochlorite is $0.1 \%$ effective, while other compounds are not as effective $(0.05 \%-0.2 \%$ for benzalkonium chloride, $0.02 \%$ for chlorhexidine digluconate) $)^{3}$. Ethanol holds the most promise not only because of its efficacy but also because there is a vast literature on the effects of ethanol, in beverages and as a disinfectant. This raises the question: if ethanol can be effectively delivered and make direct contact with a viral infection, can it be used as a treatment for COVID-19?

Any type of inhalation therapy for a pulmonary condition has the potential to be significantly more effective than a tablet-based on the direct administrative route. Economical and reliable technology that is well understood has been developed and tested by tens of millions of users for "vaping." While there are negative connotations with this term, the health effects are typically attributed to the long term use of additives such as nicotine and the vaping juice. There is a clinical trial ${ }^{6}$ about to start in the U.S., entitled "The Impact of Vaping Ethanol in the Evaluation of Impairment", at Virginia Commonwealth University (ClinicalTrials. gov Identifier: NCT03826303). From the clinical trials website; "The purpose of this research study is to find out about ethanol-containing e-cigarettes impact on ethanol breath tests, field sobriety tests, or other tests of sobriety. Ethanol is a common part of e-cigarette liquids." The technology and its bulk solvents proposed

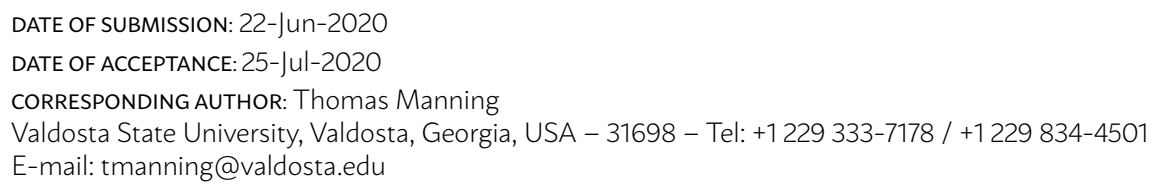


here are already being incorporated (planned) in a clinical setting ${ }^{6}$.

While there is no definitive work, the current published studies suggest that moderate doses and short-term use of the common bulk solvents (glycerin, propylene glycol) would have minimal or no health effects. There are published studies that indicate trace levels of toxic materials in the vapor generated by the glycerin-propylene glycol combination ${ }^{7}$ and that propylene glycol can be an irritant over an extended period of time ${ }^{8,9}$. Glycerin is widely used in the food and health care industries and published work indicate it has anti-viral and anti-bacterial properties ${ }^{10}$. It is also used in formulations to increase the uptake rate and efficacy of certain drugs, presumably through its ability to dehydrate biomaterials ${ }^{11}$.

Our suggestion is to consider a human trial in which a glycerin-propylene glycol-ethanol formulation is administrated as an inhaled vapor for COVID-19 patients. It is not being suggested as a cure, but rather a method that might work to reduce the viral load in the patient's lungs. Because this solvent combination is already being used by many of the world's citizens, including some that are stricken with COVID-19, this might eliminate or reduce some of the regulations a new treatment may be required to meet. We are proposing a formulation that potentially can:

1. reduce the viral load in the lungs (see table 1) to the benefit of a patient's immune system;

2.reduce the number of active viruses that are dissipated by an infected individual through sneeze or cough.
To provide an example from our work, in one trial each 4-second inhalation consists of $7.4 \mathrm{uL}$ of ethanol, which can potentially inactivate five percent of the total viral load. This does not take into account the effect of the other two bulk solvents. Two treatments of $0.8 \mathrm{~mL}$ would hypothetically be enough to completely inactivate the entire viral load in the lungs. We do not anticipate it will approach this level of efficacy, but the inhalation administration may control or reduce the activity of the viral infection. While dosing studies would be needed, an educated guess is a patient might utilize between 2 and 10 treatments per day, each consisting of 0.5 to $0.8 \mathrm{~mL}$ volume. A total treatment might last between one and three weeks with the goal of lowering the viral load to a level where the body's immune system can become effective again.

The vaporizer used for our different compositions has a consistent delivery quantity (see graph 1) for a range of compositions tested. The vaporization technology is economical, rugged, easily cleaned, and well understood. The use of ethanol in these devices is currently being evaluated in a U.S. Clinical trial not for medical efficacy, but for the ability of ethanol to impair a user. An aerosol generator in which the ethanol might be delivered and dissolved in water is not considered because of the dilution factor and subsequent loss of efficacy. Glycerin has antiviral properties and has the approval of the FDA to treat wounds. Propyleneglycol (PG) is used in pharmaceutical formulations. Some studies indicate it aids in the uptake and penetration rate of different pharmaceuticals, including antivirals and fatty acids.

TABLE 1. CALCULATION OF THE AMOUNT OF ETHANOL DELIVERED TO THE LUNGS DURING INHALATION; ALL VALUES ARE ROUGH ESTIMATES BUT ARE DERIVED FROM PUBLISHED VALUES FOR OTHER VIRUSES OR OUR EXPERIMENTS.

\footnotetext{
a. The COVID-19 viral load is estimated at 20 million virus per $\mathrm{mL}$ of lung tissue.

b. With $6000 \mathrm{~mL}$ of lung tissue (adult) there are 120 billion viruses, rounded up to 200 billion viruses (note many of these are in infected cells).

c. Assume it takes ten million molecules of ethanol to disinfect/inactivate one virus.

d. The density of ethanol is about 0.8 grams $/ \mathrm{mL}$.

e. 200 billion viruses will need (10 million ethanol's $\times 200$ billion $)=2 \times 10^{18}$ molecules of ethanol ( molar mass $=46 \mathrm{~g} / \mathrm{mol}$ )

f. $\left(2 \times 10^{18} \mathrm{EtOH}\right) /\left(6 \times 10^{23} \mathrm{EtOH} / \mathrm{mol}\right)=3.3 \times 10^{-6}$ moles ethanol

g. $\left(3.3 \times 10^{-6} \mathrm{~mol}\right) \times(46 \mathrm{~g} / \mathrm{mol})=0.000153$ grams $=153 \mathrm{ug}$ ethanol or $122.4 \mathrm{uL}$.

In our vaporizer, an estimate is 18 pulls by the vacuum, each lasting 4 seconds, to completely vaporize a $0.8 \mathrm{~mL}$ solution composed of: (i). 4 parts Propylene Glycol, (ii). 1 part Glycerin, (iii). 1 part EtOH, $(0.133 \mathrm{~mL}$ of EtOH in the $0.8 \mathrm{~mL}$ solution)

Each four-second inhalation consists of $7.4 \mathrm{uL}$ of ethanol, which is enough to inactivate approximately six percent of the viral load*. This does not take into account the efficacy of the other two bulk solvents. Two treatments of 0.8 ml would hypothetically be enough to completely inactivate the entire viral load in the lungs. We do not anticipate it will approach this level of efficacy but the administration may control or reduce the activity of the viral infection.

* These values will change with the type of vaporizer used, the inhalation capabilities of the user, etc.
} 
GRAPH 1. A TOTAL OF FIFTY PULLS (SEPARATE INHALATIONS) WAS USED WITH A FATTY ACIDGLYCERIN COMPOSITION AND ITS DELIVERY (MEASURED BY THE LOSS OF MASS IN THE VAPORIZER) WAS FAIRLY CONSTANT OVER $50(<4$ SECOND) PULLS. THE VOLUME VAPORIZED VARIES WITH THE COMPOSITION OF THE SOLVENT.

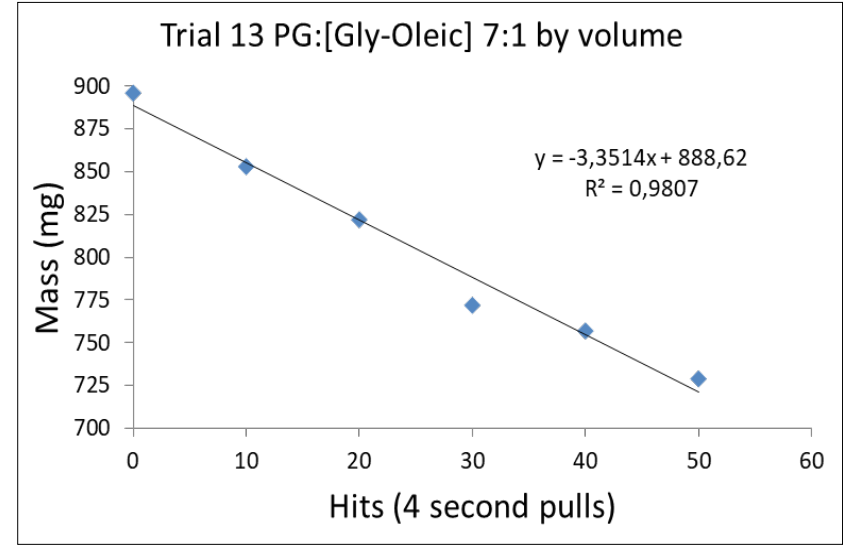

The COVID-19 pandemic is still a significant problem in many Latin American countries, with Brasil having the highest number of infections and death, followed by Peru ${ }^{12}$. Given the lack of treatments for this disease and the relative safety of this approach, we suggest ethanol might be considered for a clinical trial.

\section{REFERENCES}

1. The Global Health Network. Latin America COVID-19 [cited 2020 May 27]. Available from: https://coronavirus.tghn.org/regional-response/ latin-america/

2. Kampf G. Efficacy of ethanol against viruses in hand disinfection. J Hosp Infect. 2018;98(4):331-8.

3. Kampf G, Todt D, Pfaender S, Steinmann E. Persistence of coronaviruses on inanimate surfaces and their inactivation with biocidal agents. J Hosp Infect. 2020;104(3):246-51.

4. Lai CC, Shih TP, Ko WC, Tang HJ, Hsueh PR. Severe acute respiratory syndrome coronavirus 2 (SARS-CoV-2) and coronavirus disease-2019 (COVID-19): the epidemic and the challenges. Int I Antimicrob Agents. 2020;55(3):105924.

5. Oxford JS, Lambkin R, Gibb I, Balasingam S, Chan C, Catchpole A. A throat lozenge containing amyl meta cresol and dichlorobenzyl alcohol has a direct virucidal effect on respiratory syncytial virus, influenza A and SARS-CoV. Antivir Chem Chemother. 2005;16(2):129-34

6. ClinicalTrials.gov. The impact of vaping ethanol in the evaluation of impairment. [cited 2020 May 25]. Available from: https:/clinicaltrials.gov/ct2/ show/NCT03826303

7. Ooi BG, Dutta D, Kazipeta K, Chong NS. Influence of the E-cigarette emission profile by the ratio of glycerol to propylene glycol in E-liquid composition. ACS Omega. 2019;4(8):13338-48.

8. Phillips B, Titz B, Kogel U, Sharma D, Leroy P, Xiang Y, et al. Toxicity of the main electronic cigarette components, propylene glycol, glycerin, and nicotine, in Sprague-Dawley rats in a 90-day OECD inhalation study complemented by molecular endpoints. Food Chem Toxicol. 2017;109(Pt 1):315-32.

9. National Academies of Sciences, Engineering, and Medicine; Health and Medicine Division; Board on Population Health and Public Health Practice; Committee on the Review of the Health Effects of Electronic Nicotine Delivery Systems; Eaton DL, Kwan LY, Stratton K, eds. Toxicology of E-cigarette
Our ongoing work with drug development for tuberculosis and cancer has focused on a novel approach to the treatment of these diseases. In addition to the pharmaceutical agent, additional components are included in the formulation at low levels, including antagonists, molecular level building blocks, nutrients, and an additional toxic complex. These additional species are aimed at both accelerating certain processes in the target and interfering with others, weakening it and allowing the primary species to work more effectively. A future endeavor in this area might include the testing of additives such as ammonium chloride, specific fatty acids, glucose, DMSO, a copper-lysine complex, etc. at low levels to increase the efficacy of the alcohol. We have been considering inhalation as a method for the treatment of pulmonary MTb infections and pivoted to viral infections when the current pandemic surfaced. The process of vaporization is widely used in our society and the use of ethanol as a disinfectant and more specifically as an anti-viral agent that has efficacy against COVID-19 has some acceptance by the medical community. Links to representative publications from our group related to COVID, tuberculosis, and cancer are provided ${ }^{13-17}$ constituents. Washington: National Academies Press (US); 2018. [cited 2020 May 25]. Available from: https://www.ncbi.nlm.nih.gov/books/NBK507184/

10. Marshall L, Ghosh MM, Boyce SG, MacNeil S, Freedlander E, Kudesia G. Effect of glycerol on intracellular virus survival: implications for the clinical use of glycerol-preserved cadaver skin. Burns. 1995;21(5):356-61.

11. Björklund S, Engblom J, Thuresson K, Sparr E. Glycerol and urea can be used to increase skin permeability in reduced hydration conditions. Eur I Pharm Sci. 2013;50(5):638-45.

12. Ríos AM. Latin America: COVID-19 cases 2020, by country. [cited 2020 May 27]. Available from: https://www.statista.com/statistics/1101643/ latin-america-caribbean-coronavirus-cases/

13. Manning T], Thomas-Richardson |, Cowan M, Beard T. Vaporization, bioactive formulations and a marine natural product: different perspectives on antivirals. Drug Discovery Today. 2020;25(6):956-8.

14. Manning T], Plummer SEB, Baker TA. Tablet composition for anti-tuberculosis antibiotics. United States Patent. Patent No.: US 10,335,374 B2. [cited 2020 May 27]. Available from: https://patentimages.storage.googleapis. com/41/6f/36/3a189e23afc34a/US10335374.pdf

15. Manning T, Slaton C, Myers N, Patel PD, Arrington D, Patel Z, et al. A Copper 10-Paclitaxel crystal; a medicinally active drug delivery platform. Bioorg Med Chem Lett. 2018;28(20):3409-17.

16. Manning TI, Wilkerson $K$, Holder T, Bartley AC, Jackson C, Plummer S, et al. Pharmacokinetic studies of a three-component complex that repurposes the front line antibiotic isoniazid against Mycobacterium tuberculosis. Tuberculosis (Edinb). 2017;107:149-55.

17. Manning T, Plummer S, Woods R, Wylie G, Phillips D, Krajewski L. Cell line studies and analytical measurements of three paclitaxel complex variations. Bioorg Med Chem Lett. 2017;27(12):2793-9. 